\title{
Árboles del Valle Central de Costa Rica: reproducción guaba (Inga marginata Willd.)
}

\section{Trees of the Central Valley of Costa Rica: reproduction guaba (Inga marginata Willd.)}

\author{
Freddy Rojas-Rodríguez¹ • Gustavo Torres-Córdoba²
}

\begin{abstract}
The following issue presents a brief description about the "guaba" tree (Inga marginata Willd.), including information about its phenology which directly relates to fruit recollection, seed treatment, nursery, and germination processes.
\end{abstract}

Keywords: Phenology, seeds treatments, management at nursery, germination.

\section{Resumen}

Se presenta una breve descripción del árbol "guaba" (Inga marginata Willd.), información sobre fenología como base para la recolección de frutos, el manejo de las semillas, la viverización y el proceso de germinación.

Palabras clave: Fenología, manejo de semillas, viverización, germinación, árboles.

1. Consultor Independiente; Cartago, Costa Rica; freddyrojasrodriguez@gmail.com

2. Tecnológico de Costa Rica, Escuela de Ingeniería Forestal;

Cartago, Costa Rica; gtorres@tec.ac.cr; (+506) 2550- 2039
Recibido: 26/09/2018 


\section{Taxonomía}

Nombre científico: Inga marginata Willd.

Nombre común: Guaba, cuajiniquil negro

Familia: Fabaceae-Mimosaceae

Origen: Nativa

Distribución en el mundo: Desde México hasta el norte de Argentina y Paraguay.

Distribución en Costa Rica: Presente en los bosque húmedos y muy húmedos de los 0 a los 1400 msnm [1]. Ampliamente distribuida, a veces como sombra de café, en ambas vertientes de Costa Rica.

\section{Descripción}

Árbol grande semicaducifolio, de copa tipo globosa, densa, compacta, follaje brillante. Fuste ramificado desde la base. Corteza lisa, lenticelada, café rojiza.

Las hojas son paripinnadas, alternas, con dos pares de foliolos, elípticos, ápice agudo, glabros, brillantes en el haz, con glándulas interfoliares. Los brotes u hojas jóvenes son rojizas.

Las inflorescencias son axilares, perfumadas, cubren completamente el árbol, de color blanco, muy

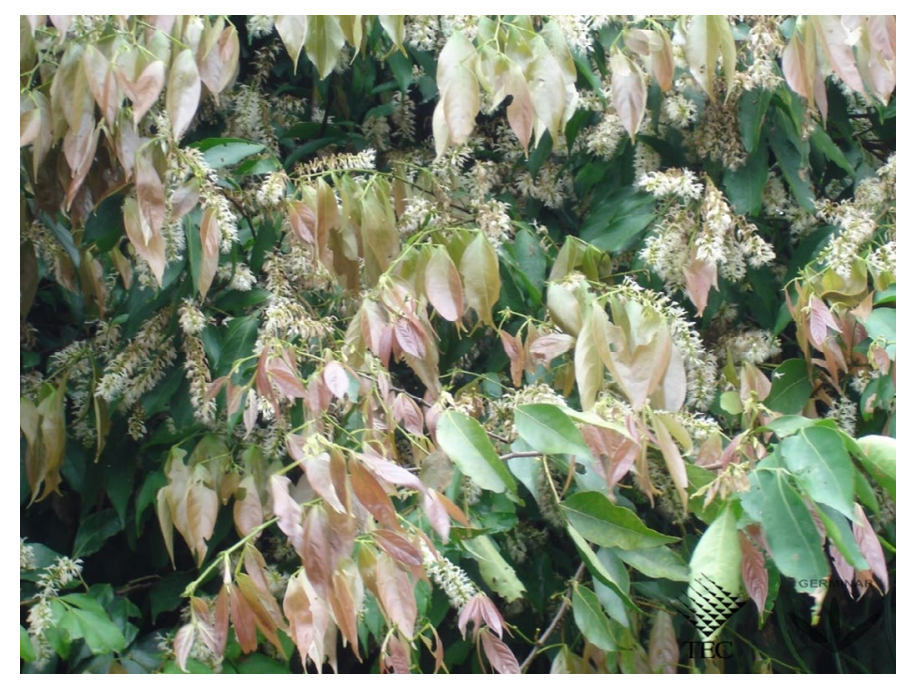

Figura 1. Perfil de Guaba.

Figure 1. Profile of "Guaba" tree. llamativas. Es el alimento favorito de la mariposa morfo (Morpho cypris).

La copa densa, sus tonos y la floración abundante la hacen una excelente especie para fines ornamentales, también como leña [2].

El fruto es carnoso tipo vaina indehiscente (figura 1), oblongo, de 6 a $14 \mathrm{~cm}$ de largo y 1,5 a 1,8 cm de grueso y abultado a la altura de las semillas, la semilla es ovoide, de 1 a $1,5 \mathrm{~cm}$ de largo y $0,8 \mathrm{~cm}$ de ancho, semi aplanada, de color verde al madurar, carnosa, cubierta totalmente por un arilo blanquecino, jugoso, dulce y sabroso [3].

\section{Dendrofenocronograma}

Se presenta a continuación información fenológica de guaba para el Valle Central de Costa Rica

Cuadro 1. Dendrofenocronograma del guaba en el Valle Central, Costa Rica.

Table 1. Tree phenology through time in gruaba, Central Valley, Costa Rica.

\begin{tabular}{|c|c|c|c|c|c|c|c|c|c|c|c|c|}
\hline \multirow{2}{*}{ Características } & \multicolumn{12}{|c|}{ Meses del año } \\
\hline & $E$ & $F$ & $\mathrm{M}$ & A & M & $\mathrm{J}$ & J & A & $\mathrm{s}$ & 0 & $\mathrm{~N}$ & D \\
\hline \multicolumn{13}{|l|}{ Hojas } \\
\hline \multicolumn{13}{|l|}{ Flores } \\
\hline Frutos verdes & & & & & & & & & & & & \\
\hline Frutos maduros & & & & & & & & & & & & \\
\hline
\end{tabular}

\section{Manejo de semilla y viverización}

Los frutos de guaba se recolectan, en el Valle Central de Costa Rica, entre los meses de abril y junio. La madurez de estos se reconoce por su tamaño, textura, corte y dispersión que es de tipo zoocora (por animales). La recolección, preferiblemente, debe hacerse mediante el uso de podadora de extensión [3].

El procesamiento para extraer las semillas se puede hacer de forma manual posterior a haber secado los frutos al sol durante un corto período o bien por un período, un tanto más largo, bajo la sombra, pero con buena aireación natural. Se puede llegar a obtener un total de 2405 semillas por kilogramo. Las semillas se siembran por el método de puntos en un sustrato a base de tierra más arena (en una relación 2:1 respectivamente). 




Figura 2. Frutos del Guaba.

Figure 2. Fruits of "Guaba" tree.

Éstas se deben cubrir apenas superficialmente, siendo que la germinación se experimenta entre los 10 y 25 días después de la siembra, con un porcentaje que, dependiendo de la calidad de la semilla, varía entre un 60 y un $84 \%$ [3].

Las plántulas se encuentran listas para su repique o trasplante, bajo el sistema de producción en bolsa plástica, tres semanas posteriores a la germinación. En cuanto al mantenimiento durante la viverización, es recomendable aplicar sombra por un periodo no mayor a los 8 días, así como fertilización química u orgánica en caso requerido [3].

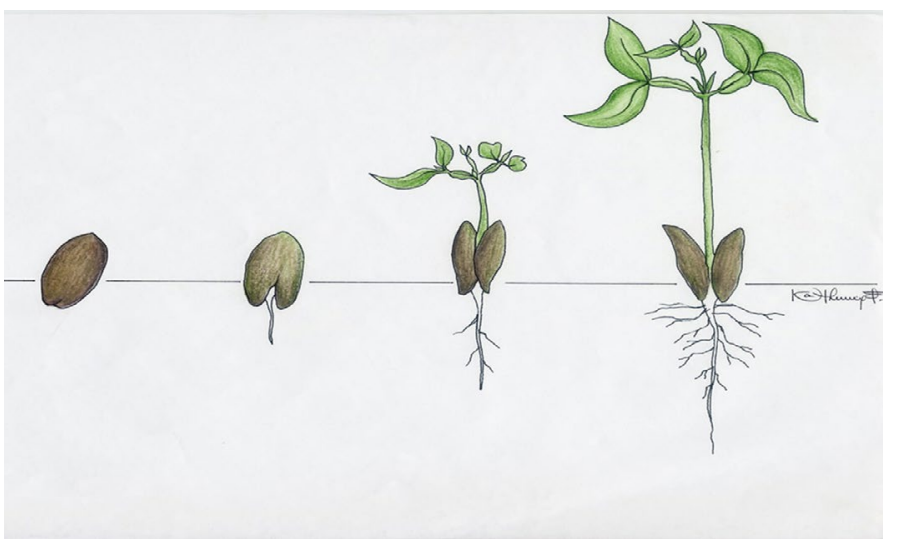

Figure 3. Proceso de germinación del guaba.

Figure 3. Seed germination of "guaba" tree.

\section{Proceso de germinación}

Como se puede observar en la figura 3 , el tipo de germinación de la guaba es semihipógea.

\section{Referencias}

[1] F. Morales, M. Montero, A. Castillo y C. Rosas, Árboles y arbustos para uso urbano en el Valle Central, Costa Rica. 1ra edición. Heredia, Costa Rica: INBio. 2012.

[2] N. Zamora y T. Pennington, Guabas y cuajiniquiles de Costa Rica. 1ra edición. Heredia. Costa Rica: INBio. 2001.

[3] C. Torres, D. Carvajal, F. Rojas y M. Arguedas, "Reproducción de especies arbóreas y arbustivas de la región central de Costa Rica (Germinar 2)", 2011. Disponible: http://www.tec. ac.cr/sitios/Docencia/forestal/Germinar/germinar\%202. html

\section{Este artículo debe citarse como:}

Rojas-Rodríguez, F., \& Torres-Córdoba, G. (2018). Árboles del Valle Central de Costa Rica: reproducción guaba (Inga marginata Willd.). Revista Forestal Mesoamericana Kurú, 16(38), 72-74. doi. 10.18845/rfmk.v16i38.3999 